\title{
Intergenerational Differences in Materialist and Post-materialist Values in a Sample of Hispanic New York City Residents*
}

\author{
Diferencias intergeneracionales en valores materialistas \\ y post-materialistas en una muestra de residentes \\ hispanos de la ciudad de Nueva York
}

Recibido: junio 10 de 2012 | Revisado: agosto 20 de 2012 | Aceptado: diciembre 26 de 2012

\author{
JESÚS GIL ROALES-NIETO ** \\ FRANCISCA ROSA JIMÉNEZ LÓPEZ *** \\ BRENNA O’NEILL ***** \\ Universidad de Almería, Spain \\ JUAN PRECIADO ****** \\ JACINTO MALESPÍN ******* \\ Hostos Community College, City University of New York
}

United States

doi:10.11144/Javeriana.UPSY12-3.idmp

Para citar este artículo: Roales-Nieto, J. G., J., Jiménez, R., O’Neill, B., Preciado, J., \& Malespin, J. (2013). Intergenerational differences in materialist and post-materialist values in a sample of Hispanic New York City residents. Universitas Psychologica, 12(3), 671-683. doi:10.11144/Javeriana.UPSY12-3. idmp

* This study has been supported by the Ministerio de Educación y Ciencia, Plan Nacional I+D+I, Research Project SEJ2005-05844/PSIC.

** Universidad de Almería. Catedrático de Universidad, Facultad de Psicología. Edificio A. Despacho 239.04120 Almería, España. E-mail: jgil@ual.es

**** Universidad de Almería, Almería, España. Profesora, Departamento de Enfermería y Fisioterapia.

****** Universidad de Almería, Almería, España. Becario de investigación, Facultad de Psicología.

******* Hostos Community College of the City University of New York. Bronx, NY 10451 USA. Catedrático, Departamento de Educación.

${ }^{* * * * * * * * *}$ Hostos Community College of the City University of New York. Bronx, NY 10451 USA. Adjunct Assistant Professor, Departamento de Ciencias Sociales y Conductuales.

\section{A B S T R A C T}

The present study evaluates the personal values reported by a sample of New York Hispanic residents using an open evaluation format in which the participants identified and prioritized their personal values. Four hundred and forty-five participants were assigned to one of three groups: Young $(N=159)$, Adult $(N=168)$ and Senior $(N=118)$. The values reported were categorized into post-materialist, materialist or non-classifiable. The Percentage Difference Index between post-materialist and materialist values was calculated in order to determine the value profile for each age group. The results showed that reports of personal values and values attributed to the participants' own generation were similar in Adult and Senior groups, but were very different in the Young Group, with a differential report of post-materialist values. Furthermore, exposure to American culture did not appear to have a significant effect on the reported values of NYC Hispanics. To confirm these findings, we need to conduct additional studies with larger samples of culturally diverse populations.

Key words authors

Personal values, value change, post-materialist values, descriptive study by survey. Key words plus

Cognitive Psychology, Hispanoamerica, Theory of values.

\section{RES UMEN}

Se exploran los valores en una muestra de hispanos de New York, empleando un formato abierto en el que los participantes identifican y priorizan su valores personales y los de su generación. Los 445 participantes se distribuyeron en tres grupos: Jóvenes $(N=159)$, Adultos $(N=168)$ y Mayores $(N=118)$. Los informes de valores se categorizaron como postmaterialistas, materialistas o no clasificables, y se calculó el Percentage Difference Index entre valores postmaterialistas y materialistas para determinar el perfil de valores de cada grupo. Los resultados mostraron que los informes de valores personales y generacionales fueron similares en los grupos Adulto y Mayor, y diferentes en el Grupo Joven con un reporte diferencial entre valores personales y generacionales. Por otro lado, el tiempo vivido bajo la influencia de la cultura 
norteamericana parece no tener un efecto significativo en el informe de valores para esta población. Para confirmar estos hallazgos son necesarios estudios adicionales con muestras más amplias y en poblaciones culturalmente diversas. Palabras clave autores

valores personales, cambio en valores, valores postmaterialistas, estudio descriptivo mediante encuesta.

Palabras clave descriptores

Psicología cognitiva, Hispanoamérica, Teoría de valores

\section{Introduction}

Ronald Inglehart's Theory of Intergenerational Value Change (i. e., Abramson \& Inglehart, 1992, 1995; Inglehart 1970, 1971, 1977, 1990, 1997; Inglehart \& Welzel, 2005), which was framed based on the results of the World Values Survey, suggests that people from developed countries have become more reflexive, less traditional, and more interested in values related to freedom, quality of life, and self-expression. According to this theory, older generations developed materialist values (rational-secular values) while confronting life's hardships in a social climate of scarcity and insecurity, while keeping hard work in high esteem. In contrast, newer generations have been growing up in social contexts of prosperity and security, and have been progressively incorporating a system of values that prioritize post-materialist or self-expressionist ideals related to the development of personal autonomy, harmony in personal relationships, solidarity and tolerance, well-being, and the like (i.e., Abramson \& Inglehart, 1992, 1995; Inglehart 1970, 1971, 1990, 1997; Inglehart \& Welzel, 2005; Welzel, 2010). This theory also predicts a change in values in the younger generations, while the older generations are expected to maintain a modernist profile of personal values. Moreover, some studies have reported a profound change of values in the political sector (Hunter, 1991), in the exploration of values (Tranter \& Western, 2010), and in the social evaluation of materialist values (Kasser, 2002).

Schwartz (1994) defined values as abstract beliefs about desirable end states or behaviors that transcend specific situations, guide evaluation and behavior, and can be rank-ordered in terms of relative importance. Typically, sociological and psychosocial studies evaluate values in closed-response formats in which participants select, rate or order values from a researcher's predetermined list (see, Inglehart, 1970, 1977; Rokeach, 1973; Schwartz, 2001). There are two main weaknesses associated with the mentioned studies. One is the limited number of options given to choose from, and the other is an enhanced social desirability effect, especially if data are being recorded in an interview format, with the interviewee reporting his/her values face to face in the presence of the interviewer (Roales-Nieto, 2009).

Instead of limiting the participants' responses to a specific list of standard values, an alternative is to use an open format in which participants are asked to freely write their personal values on their own words without restrictions (Roales-Nieto, 2009; Roales-Nieto \& Segura, 2010). There are several advantages to using an open format: 1 ) it reduces the effect of social desirability; 2) it reduces response time; and 3) it allows the participants to express their personal values in their own words. This study incorporates this methodology to explore change in values.

Studies from the World Values Survey (see, Inglehart \& Welzel, 2005) indicate that there has been a marked shift towards post-materialist values throughout the United States population. Other studies have shown that there are certain inconsistencies in what are called the "American Core Values" (Bahmueller, Buchanan, \& Quigley, 1991; Goren, 2005; Pantoja, 2006) and reputed Latino Core Values (Carter, Yeth, \& Mazzula, 2008; Chandler, Tsai, \& Wharton, 1999; Dennis, Basañez, \& Farahmand, 2010; Garza \& Watts, 2010; Pantoja, 2006; Pérez \& Padilla, 2000). Given the diversity of the US population, is the presumed values shift also occurring at the same pace and to the same extent in communities with deep-seated traditional values? This study attempts to delve into a deeper analysis of the American values change by studying a sample of Hispanics, the largest minority population in the US.

According to data from The US Census $\mathrm{Bu}$ reau (2010), 27\% of the New York City population is Hispanic. The presence of multiple generations 
of Hispanics in the New York City population allows us to study personal values, found in the older generations, which are made up of immigrants who arrived to the city being young, but had already developed their values in their home countries. Likewise, we can study the younger generations who were born in the USA and have formed their values in a mixed context of the Anglo and Hispanic cultures, mainly formed by the neighborhoods of The Bronx, Queens, and Upper Manhattan, in which large areas are inhabited primarily by Hispanics.

The Theory of Value Change predicted that the number of post-materialists in the population would increase with the incorporation of new generations. To measure the change in values the Percentage Difference Index ([PDI]; Abramson \& Inglehart, 1995; Miller, 1974), is calculated as the difference between the percentages of people that demonstrate the materialist and the postmaterialist value profiles. Therefore, the PDI indicates the predominance of one type of values (i.e., post-materialist) over another (i.e., materialist) at a given point in time. In fact, Inglehart (1997, p. 177, Table 5.2) wrote about a shift in the PDI in the US population from -24 (which indicates a strong predominance of materialist value) in 1981 data to +6 (which would indicate a shift to a predominance of post-materialist values) in the 1990 data. So, according to these predictions, by the time that this study was conducted (2009-2010) the PDI's of Hispanics should clearly show a post-materialist profile with a highly positive PDI.

The purpose of the study is to explore whether Hispanic value changes have followed the same pattern or one that differed from that previously reported for the US population. Using an open-ended survey methodology, this study will allow us to compare the generalizability and universality of the Theory of Value Change's predictions.

\section{Method}

\section{Participants and Design}

An analytical-transversal study design was employed (Kelsey, Thompson, \& Evans, 1986) to discretionally target five hundred individuals from two of the five New York City boroughs (Bronx 48.4\% and Manhattan with 27.2\%) with the most significant percentage of Hispanic residents (US Census Bureau, 2010). Then, returned blank and incorrectly filled out surveys were discarded; 445 participants made up the final sample, which was divided into three age groups. A Young Group made up of 159 participants who were between 18-35 years of age; an Adult Group, represented by 168 participants who were between 36 and 60 years of age; and a Senior Group, comprised of 118 participants over 60 years of age. We followed the suggestions of Hartley (2012) in the elaboration of this report.

\section{Instruments and Measures}

Values were assessed using the Report of Personal Values (RPV), which is a survey instrument with an open-ended question format where participants freely write up to a maximum of 10 values following an orderly and prioritized method (a detailed description of RPV can be found in Roales-Nieto \& Segura, 2010). The RPV contains questions related to socio-demographic data and four open-ended questions about values (Sections A, B, C \& D). In this study, we only used the questions that asked about the most important personal values (Section A), and the most important values attributed to the participant's own generation (Section B).

In Section A, the participant read the following instructions before answering:

Think of the MOST IMPORTANT PERSONAL VALUES that are driving your life. Create a list of these values where $\# 1$ is your most important value, \#2 is your second most important, until you reach a maximum of 10 values.

In Section B, the participant read the following instructions before answering:

Think of the MOST IMPORTANT PERSONAL VALUES that are driving the lives of most of the people of your generation. Create a list of these values where \#1 is the most important value you believe are 
driving their lives, $\# 2$ is their second most important until you reach a maximum of 10 values.

The values reported by participants were categorized according to the criteria of Abramson and Inglehart (1995) and Inglehart and Welzel (2005) into: (a) post-materialist or self-expression values, a cluster of values that include social tolerance, life satisfaction, expression and an aspiration to liberty and personal well being; (b) materialist or secular-rational values, referring to personal and economic security. Values that did not meet the criteria for materialist or postmaterialist were considered as (c) non-classifiable values. The Percentage Difference Index ([PDI]; Abramson \& Inglehart, 1995; Miller, 1974) was calculated between post-materialist and materialist values. The PDI indicates the predominance of one type of response (i.e., equivalent to a post-materialist value) over another (i.e., materialist value) at a given point in time for a single variable (Miller, 1974). For each group and condition, PDI values were calculated subtracting the percentage of materialist values from the percentage of post-materialist values, yielding a measure that is equivalent to a mean score (Ambramson \& Inglehart, 1995, p. 13). Resulting negative index values indicate a predominance of materialist profiles, while positive values indicate a preponderance of post-materialist profiles. The possible range of PDI values is between -100 and +100 .

\section{Procedure}

Each participant was informed of the rigorous procedure followed to ensure confidentiality and anonymity of the data. Respondents were given a copy of the SPV with instructions for completing it and statement eliciting the most sincere responses as possible. Each participant answered the survey individually, in the same order, beginning with questions related to socio-demographic data, followed by Section A, and then Section B. Participants were not able to return to a section that had already been answered. Once the survey was completed, participants put it in an envelope and sealed it. Surveys were collected during the years 2009-2010.

\section{Result}

The socio-demographic profile of participants in the final sample, which excluded invalid or incomplete surveys, is presented in Table 1. Of the 445 total sample, 159 participants were found in the Young Group (57.9\% female, $42.1 \%$ male) with a mean age of 24.4 ( $S D=4.81$, range: $18-35$ yearsold); 168 participants in the Adult Group (59.5\% female, $40.5 \%$ male) with a mean age of 44.96 $(S D=6.72$, range of 36-58 years-old $)$; and 118 participants in the Senior Group (49.2\% women, $50.8 \%$ men) with a mean age of $63.94(\mathrm{SD}=6.38$, range 60-95 years-old).

Table 1 shows fairly well balanced groups in most of the socio-demographic variables including sex, educational level and economic status, which are similar to those of the general population in their age range. Likewise, the ethnic origins of the participants reflect the geographic distribution of the Hispanic population in the NYC area.

The results produced three blocks of reported values (one for every group) with two modalities (Section A with the report of personal values, and Section B with the report of values attributed to the participants' own generation). The Young Group $(N=159)$ provided a total of 1,025 responses in the personal values section $(M=5.22 ; S D=1.86)$, and 815 responses in the section regarding generational values $(M=4.15 ; S D=1.68)$. The Adult Group $(N=168)$ provided a total of 735 responses for Section A $(M=4.77$; $S D=2.01)$ and 643 for Section $B(M=4.17 ; S D=1.7)$. Finally, the Senior Group $(N=118)$ provided 501 responses for Section $A(M=5.06 ; S D=1.94)$, and 427 for Section $\mathrm{B}(\mathrm{M}=4.31 ; \mathrm{SD}=1.63)$.

The reported values were classified as materialist, post-materialist or non-classifiable following the criteria of Abramson and Inglehart (1995) and Inglehart and Welzel (2005). Examples of post-materialist values include body worship, pleasure, entertainment, self-satisfaction, altruism, tolerance, self-esteem, solidarity and the like. Examples of materialist values include security, order, authority, work, professionalism, money, morality, responsibility. Reports of family values and religious values were considered as 
TABLE 1

Socio-Demographic Distribution of the Three Groups of Participants

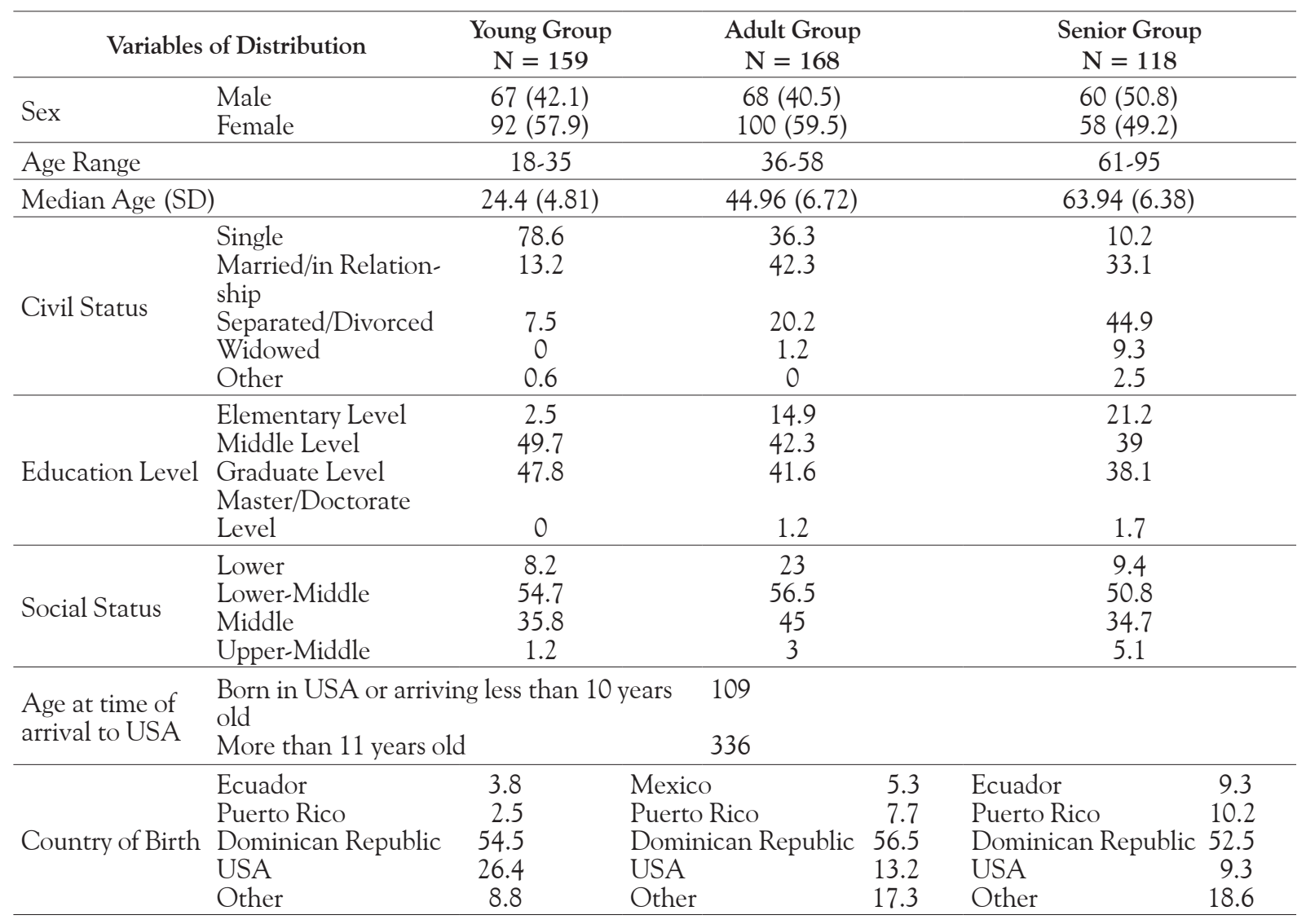

$N=445$

Source: Own Work.

non-classifiable. The participants' responses were assigned into one of the three aforementioned value categories by five independent expert researchers (judges). An agreement of at least four expert researchers was required to classify a value into one category. Fleiss's kappa was calculated when either 4 or 5 judges agreed on assigning a reported value to the same category. $86 \%$ of reported values $(N=$ $3,565)$ were assigned to one of the categories by agreement of all five judges, and $11 \%$ of reported values $(N=456)$ were assigned by agreement of 4 judges; $3 \%(N=125)$ of the reported values were eliminated for failing to meet the inter-observer agreement criteria $(\mathrm{k}=0.94)$.

Table 2 presents the criteria used for generating each participant's value profiles for personal values and values attributed to the participant's own gen- eration. The participants' profiles were developed based on the number of reported materialist and postmaterialist values (non-classifiable values were not considered). A postmaterialist profile of values was defined as having reported a majority (more than $50 \%$ of values reported) of postmaterialist values. Likewise, materialist profile of values was defined as having reported a majority of materialist values. Any other combination of values was included as an undefined profile of values.

A statistical analysis by means of contingency tables with Pearson's $\chi^{2}$ and standardized residual (SR -a measure of the degree to which an observed chi-square cell frequency differs from the value that would be expected on the basis of the null hypothesis) indicate that there are neither significant differences between the reports on personal values 
TABLE 2

Criteria for Categorization of the Value Profiles

\begin{tabular}{llll}
\hline Data & $\begin{array}{l}\text { Post-Materialist Profile of } \\
\text { Personal Values }\end{array}$ & $\begin{array}{l}\text { Materialist Profile of Per- } \\
\text { sonal Values }\end{array}$ & $\begin{array}{l}\text { Undefined Profile of Per- } \\
\text { sonal Values }\end{array}$ \\
\hline $\begin{array}{l}\text { All of the values reported } \\
\text { by each participant as per- } \\
\text { sonal values }\end{array}$ & $\begin{array}{l}\text { Report of a majority of } \\
\text { post-materialistic personal } \\
\text { values. }\end{array}$ & $\begin{array}{l}\text { Report of a majority of ma- } \\
\text { terialistic personal values. }\end{array}$ & $\begin{array}{l}\text { Any other combination of } \\
\text { personal values. }\end{array}$ \\
\hline Data & $\begin{array}{l}\text { Post-Materialist Profile of At- } \\
\text { tributed Generation's peer } \\
\text { Values }\end{array}$ & $\begin{array}{l}\text { Materialist Profile of At- } \\
\text { tributed Generation's peer } \\
\text { Values }\end{array}$ & $\begin{array}{l}\text { Undefined Profile of Attri- } \\
\text { buted Generation's peer } \\
\text { Values }\end{array}$ \\
\hline $\begin{array}{l}\text { All of the values reported } \\
\text { by each participant as gen- } \\
\text { eration's peer values }\end{array}$ & $\begin{array}{l}\text { Report of a majority of post- } \\
\text { materialistic generation's } \\
\text { peer values. }\end{array}$ & $\begin{array}{l}\text { Report of a majority of ma- } \\
\text { terialistic generation's peer } \\
\text { values. }\end{array}$ & $\begin{array}{l}\text { Any other combination of } \\
\text { values. }\end{array}$ \\
\hline
\end{tabular}

Source: Own Work.

and on values attributed to their own generation, nor are there differences along the socio-demographic variables analyzed for the three groups of participants (i.e., sex, civil status, education level, social status, country of birth, and age at time of arrival to the US).

Age at time of arrival is presumed to have a role on the formation of values when immigrating to a cultural context different from that of origin. To assess its potential impact, age at time of arrival to the US was analyzed in two different ways. First, two categories were considered: (1) born in US or arrived at less than 10 years of age, and (2) arrived in USA at 11 years of age or older. Second, participants were grouped into five distinct categories to examine the sample in more detail: (1) born in US or arrived with less than 5 years of age, (2) arrived between ages 6 and 10 years, (3) arrived between ages 11 and 20 years, (4) arrived between ages 21 and 30 years, and (5) arrived in USA at over 31 years of age. Statistical analysis performed on the two categories, and the five sub-groupings revealed no significant differences between age at time of arrival and the reported values.

Results on personal values of the total sample indicate a strong predominance of materialist values. A total of 271 participants (60.9\%) were categorized as having a materialist value profile, while only 39 (8.7\%) had a post-materialist values profile, with the other 135 participants (30.3\%) having non-classifiable values, mainly because of the predominance of family-related values. Similarly, the results on values attributed to the participants' own generation of the entire sample show a preponderance of materialistic values, which is similar to personal values, though with less pronounced differences. A total of 204 participants (45.8\%) ended up with materialist profiles, $122(27.4 \%)$ reported post-materialist values,

\section{TABLE 3}

Percentage of Participants Showing a Post-Materialist, Materialist, and Undefined Profiles Based on Personal and Generation's Peer Values Reported

\begin{tabular}{|c|c|c|c|c|}
\hline Groups & Values Reported & Post-materialist Profile & Materialist Profile & Undefined Profile \\
\hline \multirow{2}{*}{ Young } & Personal & 6.3 & 66 & 27.7 \\
\hline & Generation's peer Values & 47.2 & 31.4 & 21.4 \\
\hline \multirow{2}{*}{ Adult } & Personal & 11.3 & 61.3 & 27.4 \\
\hline & Generation's peer Values & 11.9 & 47 & 41.1 \\
\hline \multirow{2}{*}{ Senior } & Personal & 6.8 & 61.9 & 31.3 \\
\hline & Generation's peer Values & 20.3 & 50.9 & 28.8 \\
\hline
\end{tabular}

Source: Own Work. 
-PostmaterialistProfile MaterialistProfile Undefined Profile

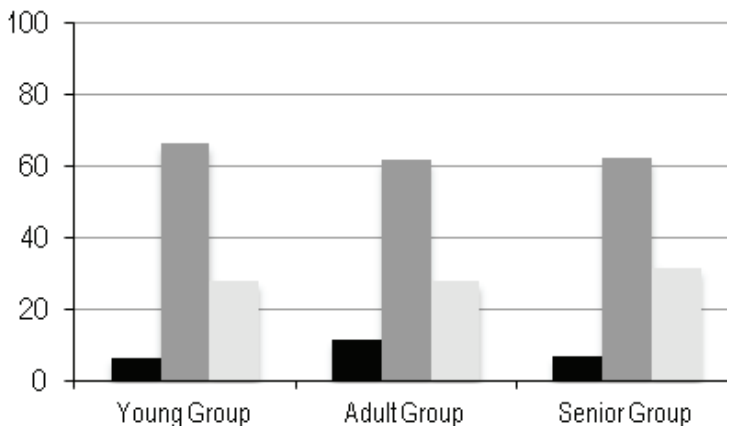

Figure 1. Personal Value Profiles for all Groups. Source: Own Work.

-PostmaterialistProfile MaterialistProfile UndefinedProfile

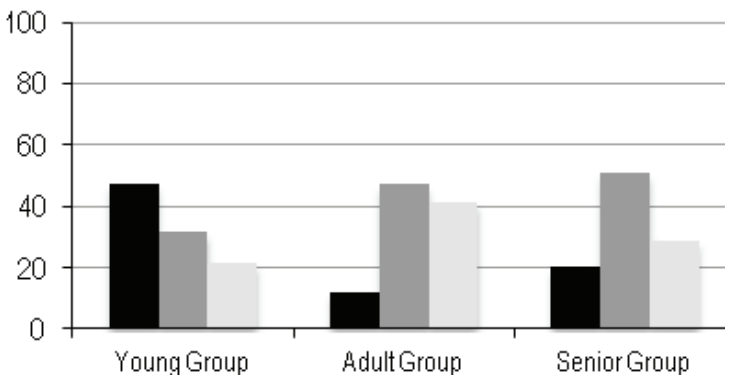

Figure 3. Generation's Peer Values Profiles for all Groups.

Source: Own Work.

and 119 (26.7\%) had a profile of non-classifiable values, also mainly because of the predominance of family-related values that were reported.

Table 3 shows the three value profiles generated for each of the groups based on both personal and on values attributed to their generation's peers responses. Figure 1 shows the distribution of personal value profiles for all groups, and Figure 2 shows the intergenerational comparison of personal values profiles. Figure 3 shows the graphic representation of the generational values profiles of the three groups of participants. Figure 4 shows the intergenerational comparison of generational values profiles.

These results indicate a very similar distribution of values reported in the Adult and Senior Groups, with profiles remarkably materialistic for both personal as well as for values attributed to peers of their

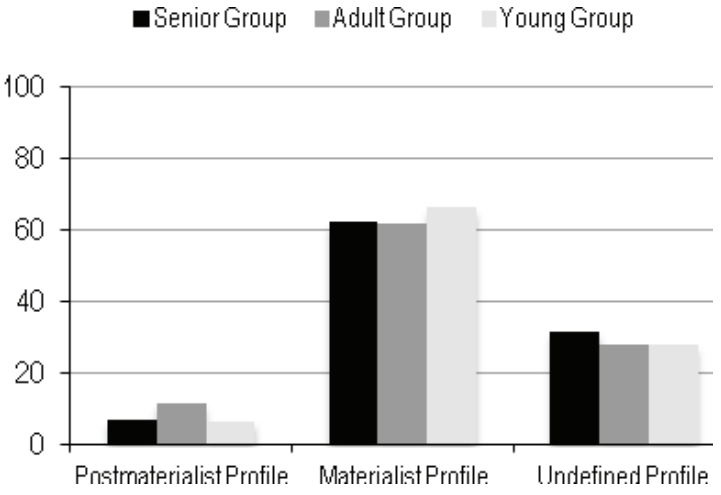

Figure 2. Intergenerational Comparison of Personal Values Profiles.

Source: Own Work.

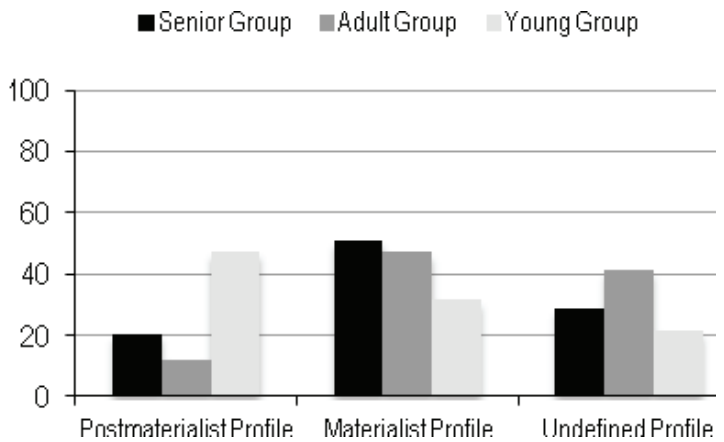

Figure 4. Intergenerational Comparison of Generation's Peer Values Profiles.

Source: Own Work.

own generation. In the Young Group, $66 \%$ of participants demonstrated a materialist personal value profile and only $6.3 \%$ demonstrated a post-materialistic profile. These results contrast strongly with the profile of values attributed to peers of the young participants' generation, with $31.4 \%$ reporting post-materialist value profile as characteristics of their generation's peers. These differences can be seen in Figure 3, where a marked contrast can be observed among the reports of the Young Group.

The statistical analysis by means of contingency tables with SR and Pearson's $\chi^{2}$ (see Table 4) only showed significant differences between the value profiles reported for groups on values attributed to the participants' own generation. $\left(\chi^{2}=45.336\right.$; $p=<0.001)$. The analysis of the SR indicates that the differences are centered in the Young and Adult Groups, considering the Senior Group's re- 
TABLE 4

Results of between Group Statistical Analysis of Personal and Generation's Peer Values Profiles

\begin{tabular}{|c|c|c|c|c|}
\hline \multicolumn{5}{|c|}{ Contingency table Group $\mathrm{x}$ Personal Values Profile } \\
\hline & & Materialist & Post-materialist & \multirow{4}{*}{$\begin{array}{c}\chi^{2}=1.735 \\
p=0.42\end{array}$} \\
\hline Young & $\begin{array}{l}\text { Observed } \\
\text { Expected frequency } \\
\text { Corrected error }\end{array}$ & $\begin{array}{c}104 \\
100.5 \\
1.2\end{array}$ & $\begin{array}{c}11 \\
14.5 \\
-1.2 \\
\end{array}$ & \\
\hline Adult & $\begin{array}{l}\text { Observed } \\
\text { Expected frequency } \\
\text { Corrected error }\end{array}$ & $\begin{array}{c}106 \\
109.3 \\
-1.1\end{array}$ & $\begin{array}{c}19 \\
15.7 \\
1.1\end{array}$ & \\
\hline Senior & $\begin{array}{l}\text { Observed } \\
\text { Expected frequency } \\
\text { Corrected error }\end{array}$ & $\begin{array}{c}61 \\
61.2 \\
-0.1 \\
\end{array}$ & $\begin{array}{c}9 \\
8.8 \\
0.1\end{array}$ & \\
\hline \multicolumn{5}{|c|}{ Contingency table Group $x$ Generation's peer Values } \\
\hline & & Materialist & Post-materialist & \multirow{4}{*}{$\begin{aligned} \chi^{2} & =45.336 \\
p & <0.001\end{aligned}$} \\
\hline Young & $\begin{array}{l}\text { Observed } \\
\text { Expected frequency } \\
\text { SR }\end{array}$ & $\begin{array}{c}52 \\
80.1 \\
-6.6\end{array}$ & $\begin{array}{c}76 \\
47.9 \\
6.6\end{array}$ & \\
\hline Adult & $\begin{array}{l}\text { Observed } \\
\text { Expected frequency } \\
\text { SR }\end{array}$ & $\begin{array}{l}93 \\
72 \\
5\end{array}$ & $\begin{array}{l}22 \\
43 \\
-5\end{array}$ & \\
\hline Senior & $\begin{array}{l}\text { Observed } \\
\text { Expected frequency } \\
\text { SR }\end{array}$ & $\begin{array}{c}59 \\
51.9 \\
1.9\end{array}$ & $\begin{array}{c}24 \\
31.1 \\
-1.9\end{array}$ & \\
\hline
\end{tabular}

Source: Own Work.

ported values were within the expected frequency (see Table 4). These differences demonstrate two tendencies shown by the Young and Adult Groups. In the Young Group, a propensity to report less materialistic and more post-materialistic values as typical for their generation's peers than the expected frequency (SR -6.6 y +6.6, respectively). The opposite happened in the Adult Group, which reported that the typical values of their generation's peers were more materialistic and less post-materialistic than the expected frequencies $(S R+5.0 y$ -5.0 , respectively). That is, young people perceive their generation's peers as having predominantly post-materialist values, while adults perceive their generation's peers as possessing primarily materialist values. As stated elsewhere, these betweengroup differences were not found in the report on personal values, as participants from all three groups reported their own values as being mainly materialistic (see Table 3).

The Percentage Difference Indexes that result from these data are shown in Figure 5, in which one can see that all of the PDIs generated from the personal values report are strongly negative $(-55.1$ for the Senior Group; -50 for the Adult Group; and -59.7 for the Young Group), which reflects the strong predominance of materialist values mentioned above. Correspondingly, the PDIs generated for adult and senior groups show a negative PDI which signifies a predominance of materialist values as a characteristic attributed to their generation's peers $(-30.6$ for the Senior Group, and -35.1 for the Adult Group), except in the case of the Young Group which has a PDI +15.8 (which indicates a predominance of post-materialist values).

\section{Discussion}

The main objective of the study was to test if the change in materialist and post-materialist values predicted by Inglehart's Theory for the general US population (Inglehart \& Welzel, 2005) is also occurring in the same manner on a sample of NYC Hispanics. To accomplish this, a survey with open-ended questions about personal values was used to generate value profiles within three dis- 


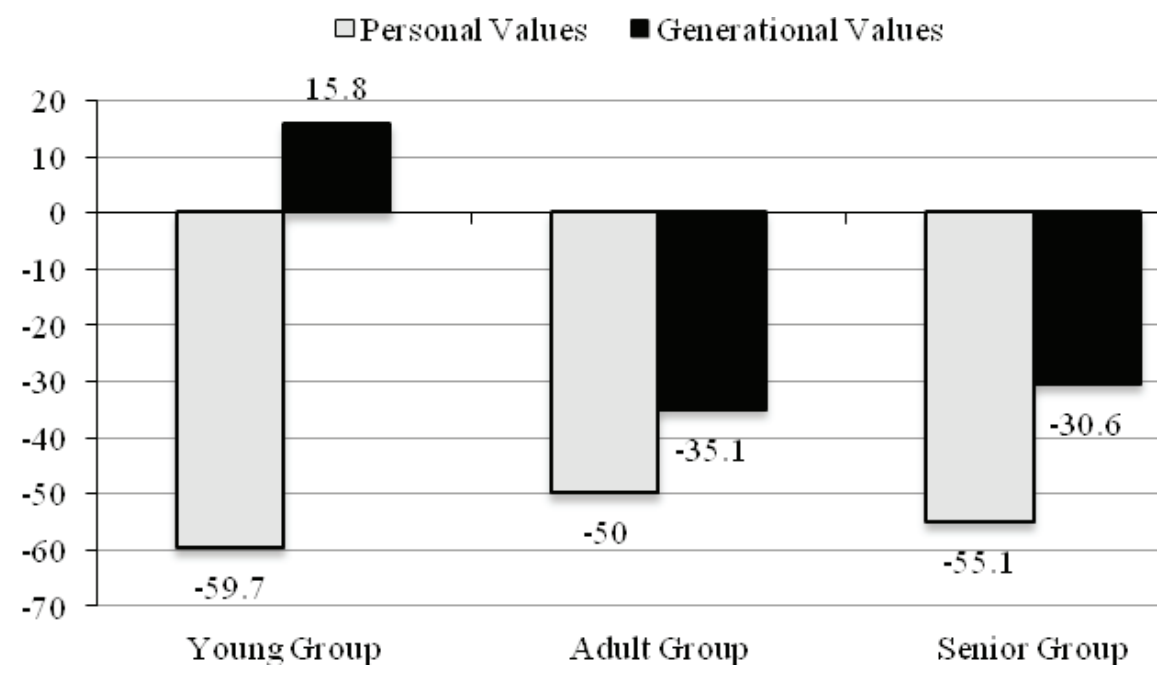

Figure 5. PDI for the Three Groups.

Source: Own Work.

tinct generations of adults. In addition, this study explored the beliefs about values attributed to the participants' own generation. This additional feature is noteworthy because it allows us to determine if the participants perceive a change in the values of others.

Previous studies (i. e., Jiménez-López, Roales-Nieto, García-Vargas, Vallejo, \& Granados [under review]; Roales-Nieto, 2009; Roales-Nieto $\&$ Segura, 2010) have shown that when employing an open-ended format methodology, which involves a prioritized list of values generated freely by the respondents, the concept of personal values appears to be very idiosyncratic with a wide range of responses across participants. Notwithstanding the variability of responses and the relative difficulty in categorizing values, the open format might produce more realistic data about personal values than closed survey format, even when subjected to traditional methods of analysis such as the PDI Index. Likewise, this study extends the use of such methodology to systematically explore intergenerational value change with a segmented population of Hispanics in the US.

Inglehart's theory predicted that with the incorporation of new generations, the number of post-materialists in the US population would increase with a total PDI change of +30 (see, Inglehart, 1997, p. 177, Table 5.2). So, according to this prediction, by the time the present data were obtained (2009-2010) the PDI should have clearly shown a post-materialist profile with a highly positive PDI. However, the results of this study confirm this prediction only for the values that the Young Group attributed to peers of their own generation. In contrast to Inglehart's theory, the reports of personal values were clearly materialist for all groups. Furthermore, the Adult and Senior Groups showed a strong materialist profile for their generation's peer values.

It could be argued that the report of personal values was slanted, with participants wanting to appear more materialistic than they actually are, but post-materialist values actually enjoy "good press" and are socially promoted (Ahuvia \& Wong, 1995). Therefore, it seems unlikely that participants in this study would want to appear different from who they really are by reporting personal values that are socially categorized as "old-fashioned" (Kasser, 2002). The contradictory and singular nature of these findings, which replicate previous studies (Jiménez-López, Roales-Nieto, García-Vargas, Vallejo, \& Granados, under review; Roales-Nieto, 2009; Roales-Nieto \& Segura, 2010), need to be explored in greater detail through future research that compare several ways to measure values.

The report for values attributed to the participants' own generation (generational peer values 
report) brings up the discussion of generational identification (e.g., seeing oneself as having the same or similar values to those of one's generation). That is, sharing values. Our results indicate that adults and seniors share values with their corresponding generations in the form of similar PDI scores. Hence, generational identification was evident between the Adult and Senior Groups.

Generational identification, however, was not apparent in the Young group because they reported personal values with a materialist PDI and attributed a strong post-materialist PDI to their generation's peer values. This could mean that young people consider themselves very different from their peers. This rupture in generational identification in the Young Group was advanced in some previous studies in Spain (Roales-Nieto, 2009; Roales-Nieto \& Segura, 2010) and needs to be thoroughly studied and replicated in order to transcend the limitations of the present study.

Results also show that a considerable percentage of participants' profiles have been listed as Undefined for the three groups, because they exhibit a mixture of materialistic and post materialistic values without predominance of either category. To help us better understand this phenomenon, future studies should systematically compare the NYC data to those from other populations. For example, is the presence of the Undefined profile (a mixture of values without clear definition) unique to the process of acculturation among the Latino population in the U.S? Or, is it a wider phenomenon also found in samples from other countries?

Furthermore, according to Abramson and Inglehart (1995, p. 13), generational replacement alone should contribute to about one point gain per year on the PDI in favor of post-materialism, but our results indicate that this effect has not taken place in this sample. Specifically, Inglehart and Oyserman (2004) have argued that "cultural change at a societal level is parallel to Individual Psychological Mechanisms of change" (p. 86). If the shift to post-materialist values or self-expression is as universal and uniform phenomenon as the mentioned authors point out, one should find a report of personal values consistent with was said for specific populations. However, the results of this study with New York Hispanics indicate that post-materialist values hold true only for the younger group but not with the intensity that the theory predicts. That is, when the younger group was asked to report the values attributed to their peers (i.e., generational values), the results show a clear post materialistic values profile, but when asked to report their own personal values, the younger group reported a less postmaterialistic profile.

Statistical analysis showed that differences and similarities between group values reports cannot be attributed to sociodemographic variables such as sex, country of birth, marital status, education level, social status and age at time of arrival to the US. Of particular interest is the finding of lack of statistical significant effect for the variable Age at time of arrival. This variable is an important one because it reflects years of exposure to the American cultural context and to an educational system that enhances the core American values. To uncover its moderator effect, it would be necessary to replicate this study with larger samples and examine the effect of Age at time of arrival against other potential indicators such as language skills, language preference at home and school, degree of acculturation, etc.

Despite the novelty and importance of the data obtained, the conclusions derived from the results should be handled cautiously because the size of the sample limits the generalization of the results to the total US Hispanic population. Further studies with representative samples of the general population should be conducted to replicate the results and confirm whether the Hispanic cultural context mitigates the value changes to postmaterialism. Additionally, our results suggest that the assessment of values using an open format procedure could produce more useful data than those obtained using closed formats (which make participants select, rate or order values from a researcher's predetermined list). Before we can reach conclusions, it will be necessary to conduct studies that could directly compare both types of procedures when measuring personal values. 
Our cross-sectional study cannot rule out that the report of values change could have been attributed to recent socio-economic conditions, which represent a time of economic crisis in the U.S. and in most Western countries (the study was conducted during 2009 and 2010). The relationship between values and socio-economic context is well known (e.g., Ross, 2008), and the theory of social change recognizes it as one of the keys to change in values linking the predominance of post-materialist values to social circumstances and economic wellbeing (i. e., Abramson \& Inglehart, 1992, 1995; Inglehart, 1970, 1990, 1997; Inglehart \& Welzel, 2005; Wetzel, 2010). It could then be hypothesized that the finding of lower than expected proportion of postmaterialists in the Young group, as predicted in the theory of social change, is due to the economic crisis.

However, a transversal study cannot reject this alternative hypothesis, nor confirm it. There are, though, additional elements that would point in the direction of rejection. For example, the difference between the report of personal values and generational values in the younger group may be used as barometer to measure the impact of the economic crisis. That is, the possible effect of the economic crisis would not have prevented young people to consider their generation much more postmaterialist than themselves (which are consistent with the prediction of the theory of change). Moreover, accepting the potential effect of the economic crisis on the values report, in fact, would suggest that the values change profile predicted by Inglehart's theory is not so universal or widespread as predicated by its supporters (i. e., Inglehart, 2008; Inglehart \& Oyserman, 2004), unless we presumed that the economic crisis has a differential impact on personal and generational values, something which has not yet been studied.

Furthermore, the possible mediator effect of the economic crisis on personal values would relate more to the formation of values during the childhood and adolescence years than with possible changes in values once they have been formed. The literature on the development and change in values indicates that personal values hardly change once established (e. g., Rockeach, 1968, 1973; Inglehart, 1977, 1997, 2008, p. 132, especially). Undoubtedly, the interaction between socioeconomic crisis and personal values is of enormous interest, but its indepth analysis is beyond the scope of this study. Additionally, and from the authors' view, using a values perspective may be useful to understand this phenomenon. That is, to what extent having one or other personal values mitigates or amplifies the effects of the economic crisis on personal life.

A final methodological weakness of the study concerns the categorization of participants into only three age groups instead of grouping participants in terms of other characteristics such as birth cohorts (e.g., generation defined as 10-year birth cohorts). Although differences found in the report of post-materialist values across age groups suggest that the simple groupings employed were adequate in capturing differences, the reduced number of participants in our study prevented us from categorizing the sample into cohorts or other age sub-groupings. Hence, it is necessary to conduct further studies with larger samples that can allow us to test for differences between distinct subgroups of young people.

Overall, partial aspects of Ronald Inglehart's approach were replicated regarding the intergenerational transformation of values in the Young Group, which showed a clear post-materialist PDI when reporting the values attributed to their generation's peers. However, the theory predicted a shift towards post-materialist values for personal values, but the present study finds a predominance of materialist profiles for all three age groups. Furthermore, our results suggest that the exposure to the American culture did not appear to have an effect on the reported values of NYC Hispanics. To confirm these findings, we need additional studies with larger samples of culturally diverse populations.

\section{References}

Abramson, P. R., \& Inglehart, R. (1992). Generational replacement and value change in eight West European societies. British Journal of Political Science, 22(2), $183-228$. 
Abramson, P. R., \& Inglehart, R. (1995). Value change in global perspective. Ann Arbor, MI: University of Michigan Press.

Ahuvia, A. C., \& Wong, N. (1995). Materialism: Origins and implications for personal well-being. In F. Hansen (Ed.), European advances in consumer research (Vol. 2, pp. 172-178). Copenhagen: Association for Consumer Research.

Bahmueller, C. F., Buchanan, J. H., Jr., \& Quigley, C. N. (Eds.). (1991). Civitas: A framework for civic education (Bulletin No. 86). Calabasas, CA: National Council for the Social Studies.

Carter, R. T., Yeth, C. J., \& Mazzula, S. L. (2008). Cultural values and racial identity statuses among Latino students. Hispanic Journal of Behavioral Sciences, 30(1), 5-23.

Chandler, C. R., Tsai, Y. -M., \& Wharton, R. (1999). Twenty years after: Replicating a study of Angloand Mexican-American cultural values. The Social Science Journal, 36(2), 353-367.

Dennis, J., Basáñez, T., \& Farahmand, A. (2010). Intergenerational conflicts among Latinos in early adulthood: Separating values conflicts with parents from acculturation conflicts. Hispanic Journal of Behavioral Sciences, 32(1), 118-135.

Garza, Y., \& Watts, R. E. (2010). Filial therapy and Hispanic values: Common ground for culturally sensitive helping. Journal of Counseling and Development, 88(1), 108-113.

Goren, P. (2005). Party identification and core political values. American Journal of Political Science, 49(4), 882-897.

Hartley, J. (2012). New ways of making academic articles easier to read. International Journal of Clinical and Health Psychology, 12(1), 143-160.

Hunter, J. D. (1991). Culture wars: The struggle to define America. New York: Basic Books.

Inglehart, R. (1970). The new Europeans: Inward or outward-looking? International Organization, 24(1), 129-139.

Inglehart, R. (1971). The silent revolution in Europe: Intergenerational change in post-industrial societies. American Political Science Review, 65(4), 991-1017.

Inglehart, R. (1977). The silent revolution: Changing values and political styles among Western publics. Princeton, NJ: Princeton University Press.
Inglehart, R. (1990). Culture shift in advanced industrial society. Princeton, NJ: Princeton University Press. Inglehart, R. (1997). Modernization and postmodernization: Cultural, economic and political change in 43 societies. Princeton, NJ: Princeton University Press.

Inglehart, R. (2008). Changing values among Western publics from 1970 to 2006. West European Politics, 31(1-2), 130-146.

Inglehart, R., \& Oyserman, D. (2004). Individualism, autonomy, and self-expression: The human development syndrome. In H. Vinken, J. Soeters $\&$ P. Ester (Eds.), Comparing cultures: Dimensions of culture in a comparative perspective (pp. 74-96). Leiden,The Netherlands: Brill.

Inglehart, R., \& Welzel, C. (2005). Modernization, cultural change, and democracy: The human development sequence. Cambridge: Cambridge University Press.

Jiménez-López, F. R., Roales-Nieto, J. G., García-Vargas, G., Vallejo, G., \& Granados, G. (under review). Report of personal values in students and professionals nursing: A preliminary study.

Kasser, T. (2002). The high price of materialism. Cambridge, MA: MIT Press.

Kelsey, J. L., Thompson, W. D., \& Evans, A. S. (1986). Methods in observational epidemiology. New York: Oxford University Press.

Miller, A. H. (1974). Political issues and trust in government 1964-1970. The American Political Science Review, 68(3), 951-972.

Pantoja, A. (2006). Against the tide? Core American values and attitudes toward US immigration policy in the mid-1990s. Journal of Ethnic and Migration Studies, 32(3), 515-531.

Pérez, W., \& Padilla, A. M. (2000). Cultural orientation across three generations of Hispanic adolescents. Hispanic Journal of Behavioral Sciences, 22(3), 390 398.

Roales-Nieto, J. G. (2009). Cambio social y cambio personal. Estudio preliminar del cambio en valores en una muestra intergeneracional. International Journal of Psychology and Psychological Therapy, 9(3), 395-420.

Roales-Nieto, J. G., \& Segura, A. (2010). Intergenerational differences in materialism and post materialism values in a Spanish sample. International 


\section{DIFERENCIAS INTERGENERACIONALES EN VALORES MATERIALISTAS Y POST- MATERIALISTAS EN HISPANOS DE NUEVA YORK}

Journal of Psychology and Psychological Therapy, 10(3), 499-512.

Rokeach, M. (1968). A theory of organization and change in value-attitude systems. Journal of Social Issues, 24(1), 13-33.

Rokeach, M. (1973). The nature of human values. New York: Free Press.

Ross, M. (2008). Los valores culturales y el desarrollo socioeconómico: una comparación entre teorías culturales. Revista de Psicología Social, 23(3), 347-365.

Schwartz, S. H. (1994). Are there universal aspects in the structure and contents of human values? Journal of Social Issues, 50(4), 19-45.

Schwartz, S. H. (2001). iExisten aspectos universales en la estructura y contenido de los valores huma- nos? In A. Ros \& V. V. Gouveia (Eds.), Psicología social de los valores humanos. Desarrollos teóricos, metodológicos y aplicados (pp. 53-77). Madrid: Biblioteca Nueva.

Tranter, B., \& Western, M. (2010). Overstating value change: Question ordering in the Postmaterial Values Index. European Sociological Review, 26(5), 571-583.

U.S. Census Bureau. (2010). U.S. Census Bureau delivers New York's 2010 census population totals, including first look at race and Hispanic origin data. Available at http://2010.census.gov/2010census/

Welzel, C. (2010). How selfish are self-expression values? A civicness test. Journal of Cross-Cultural Psychology, 41(2), 152-174. 
